\title{
Generalized Arteriosclerosis
}

National Cancer Institute

\section{Source}

National Cancer Institute. Generalized Arteriosclerosis. NCI Thesaurus. Code C35769.

Arteriosclerosis that is not localized. 